\title{
Seeing the Unseen: Breaking the Logjam of Undernutrition in Pakistan
}

\author{
Zulfiqar A. Bhutta, Haris Gazdar and Lawrence Haddad
}

\begin{abstract}
After a lost decade, there is clearly a groundswell of momentum for nutrition in Pakistan, driven by a confluence of policy, evidence and events. This momentum needs to be sustained at the national level, reinforced at the provincial and sub-provincial levels, and converted into action. The articles in this IDS Bulletin highlight some of the key features of undernutrition in Pakistan and its drivers. The correlates of undernutrition in Pakistan are no different than any other country: infection, poor diet quantity and quality, and unequal gender relations. High levels of poverty and fragility make the context for undernutrition reduction more difficult. Yet, the articles here also show that government nutrition interventions can work. But if the logjam of malnutrition in Pakistan is to be broken for good, malnutrition will have to be viewed as a development outcome - one that is a foundation for other outcomes such as economic growth and social cohesion - and this will only be achieved by viewing nutrition through a political-economy lens.
\end{abstract}

\section{Introduction}

Pakistan represents a remarkable study in contrasts; a nuclear power of almost 185 million people with an agrarian economy and periods of reasonable economic growth accompanied by static human development indicators and a chronically underperforming social sector. Nowhere is the contrast of indicators more evident than in the status of maternal and child nutrition in the country, which has seen little concerted action at a policy level. This is despite the fact that this is one area where policy relevant information has been available for decades.

The coming together of three events: the massive flooding of 2010 and 2011, which exposed chronic as well as acute undernutrition; with the recent decentralisation of health services to the provinces; and the results from the 2011 National Nutrition Survey (NNS 2011), which show an increase in stunting, have created some momentum for nutrition (Levinson, this IDS Bulletin).

First, the floods of 2010 and 2011 laid waste to a large swathe of floodplains and displaced millions of people living in abject poverty (Bhutta and Bhutta 2010). The visible faces of malnourished people shocked public health departments and United Nations (UN) agencies into action, mostly around supplementary feeding and food distribution. Second, the long awaited National Nutrition Survey was undertaken in 2011 during a period of transition and devolution of health as a subject to the provinces. The NNS 2011 marked a decade since the last such survey in Pakistan in 2001 (NNS 2001) and provided a wealth of information in relation to nutrition and micronutrient indicators and potential interventions.

Finally, in April 2010 the parliament of Pakistan passed the 18th Amendment which sought to shift the focus of politics and governance from the central government to the provinces and in the process recognised the primacy of provincial jurisdiction over key nutrition-related areas such as health, education, food and agriculture. These constitutional reforms were accompanied by significant improvements in the fiscal position of provinces over the centre. Ambiguity between the respective roles of central and provincial governments in these areas of social policy was seen as an impediment to accountability. These constitutional reforms, therefore, led to the relocation of political ownership to that tier of government which has been responsible for much of social service delivery in the first 


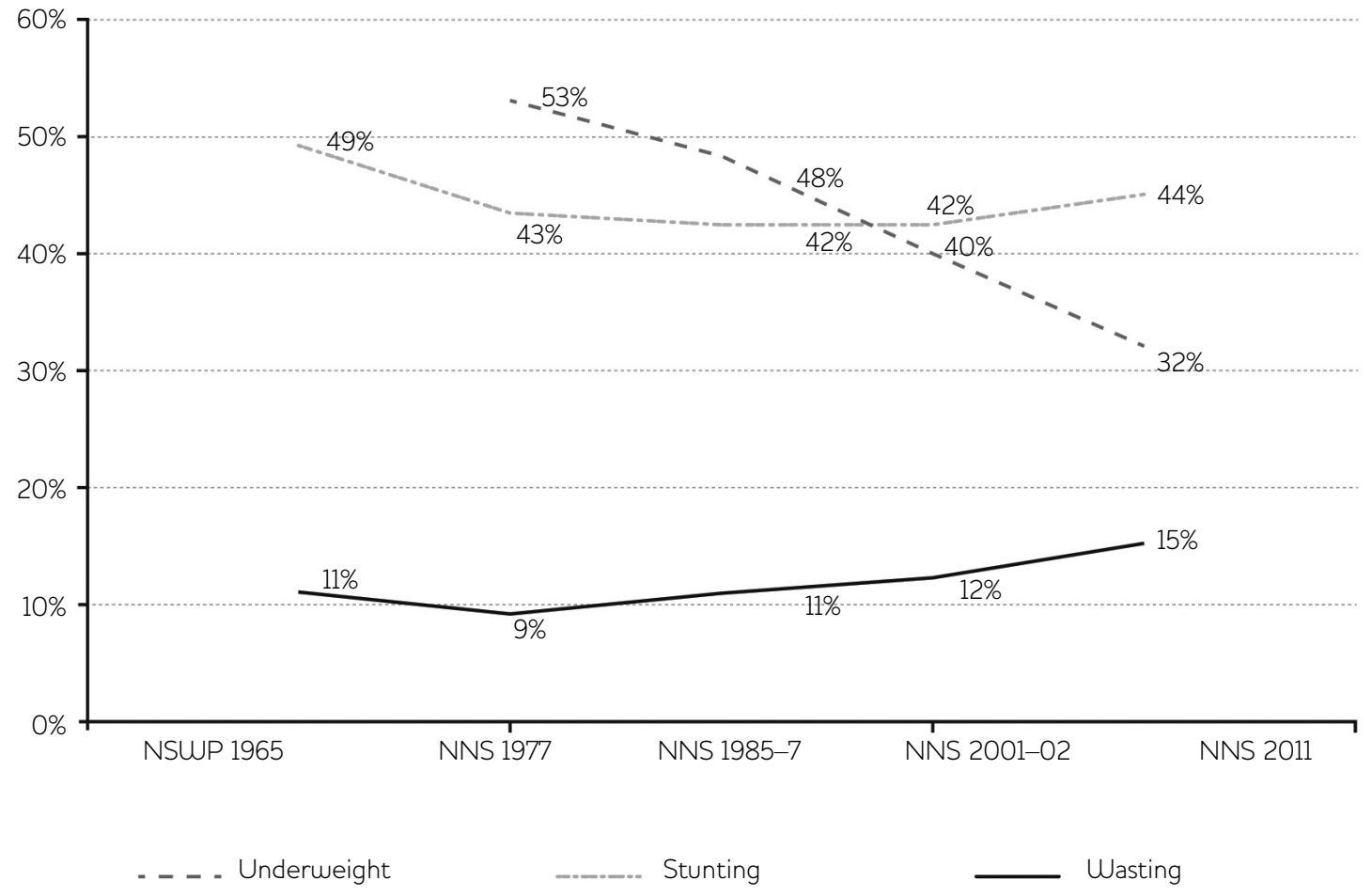

Source NNS (2011).

instance. For a complex and multi-sectoral concern such as nutrition, the shift of governance focus and fiscal resources to the provincial level offers opportunities for a fresh perspective and for innovation.

The collection of 12 articles in this IDS Bulletin represents a contribution to the potential moment of change brought about by these fortuitous circumstances. The articles do three things: (1) describe the nutrition status and its correlates and causes, (2) assess some of the interventions employed to combat undernutrition, and

(3) analyse the political context within which these interventions emerged and will have to operate in the future. They aim to give additional definition to the debate of what it is desirable and possible to do to accelerate undernutrition reduction in Pakistan and why it is essential to do so.

The articles conclude that:

1 The nutrition situation is indeed very serious with static stunting rates for under-fives over the last three decades; 42 per cent in the mid- 1980s to 44 per cent in 2011. Given the population, this actually represents a doubling of the numbers of stunted young children over this period, 6.35 million stunted under-five children in 1985, and 11.8 million in 2011.

2 While there are some nutrition-related interventions (e.g. the Tawana school feeding programme) that have been evaluated properly and which show positive impact, there are too few such nutrition interventions and evaluations nationally. Moreover when such evaluations have been conducted they have either proved unpersuasive to policymakers or come too late to have a direct influence on policy.

3 The current momentum in Pakistan in favour of nutrition, while real, is fragile. In particular, the opportunities and challenges of decentralisation need to be properly understood, as do the openings provided by significant shifts in policies concerning food security and social protection. While a number of key policy and governance issues 


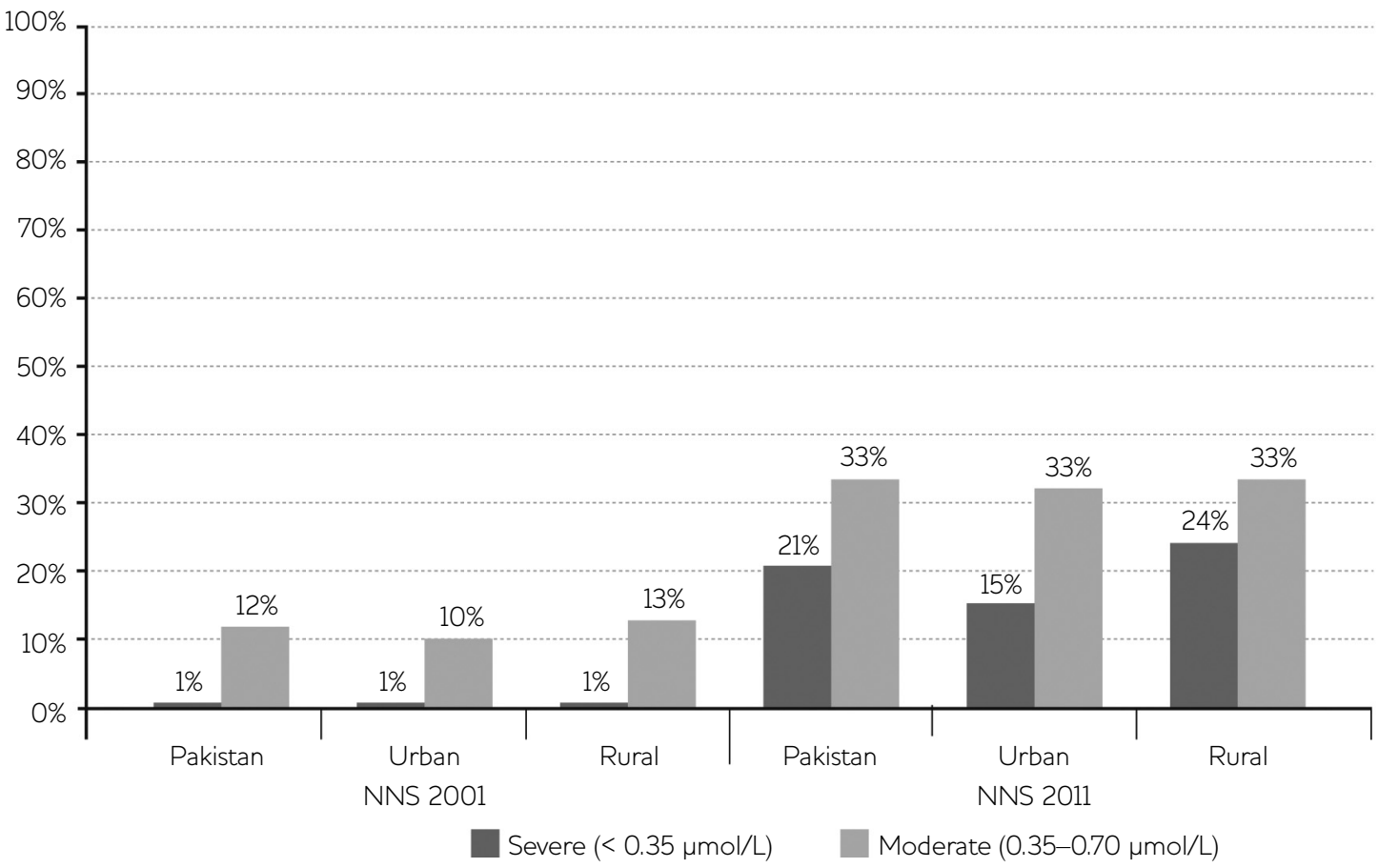

Source NNS (2001 and 2011).

remain in flux, it is clear that a national vision is desperately needed to guide priorities and to sustain and further build momentum.

\section{Nutrition status in Pakistan: importance, trends, correlates and causes}

It is estimated that in Pakistan, malnutrition is directly or indirectly responsible for 35 per cent of all under-five deaths (Bhutta et al. 2013).

Although accurate population-based estimates are not available, population-based studies indicate that close to a quarter of all newborn infants in Pakistan are low birth weight (LBW) with evidence of significant intrauterine growth retardation (Bhutta 2004). High fertility rates and family size also mean that rates of maternal depletion in Pakistan are high (Winkvist et al. 1994) and a vicious cycle of maternal and child undernutrition exists with intergenerational effects. There may also be gender-related effects. It is commonly observed that female infants who are LBW frequently remain malnourished well into adolescence and childbearing age and may further give birth to malnourished LBW infants, thus perpetuating the cycle of malnutrition. This female face of undernutrition is poorly appreciated in patriarchal androcentric societies. During infancy, females may face disproportionate bouts of infection and suboptimal feeding and care. During their reproductive years women face additional challenges of suboptimal birthspacing, multiple pregnancies and energy intake/expenditure imbalance leading to micronutrient deficiencies.

The results from NNS 2011 indicate, if anything, a worsening over the past decade of core maternal and childhood undernutrition indicators. Figure 1 shows increases in stunting and wasting. The small but notable rises in stunting and wasting have occurred despite economic growth and reduction in poverty headcount ratios over the corresponding period. With regard to micronutrient deficiencies, while iodine status had improved nationally, vitamin A status has deteriorated notably (Figure 2) and there had been little or no improvement in other areas of knowledge related to micronutrient deficiencies.

The NNS of 2011 was preceded by SMART surveys in late 2010 undertaken by the United Nations Children's Fund (UNICEF) and Aga Khan 


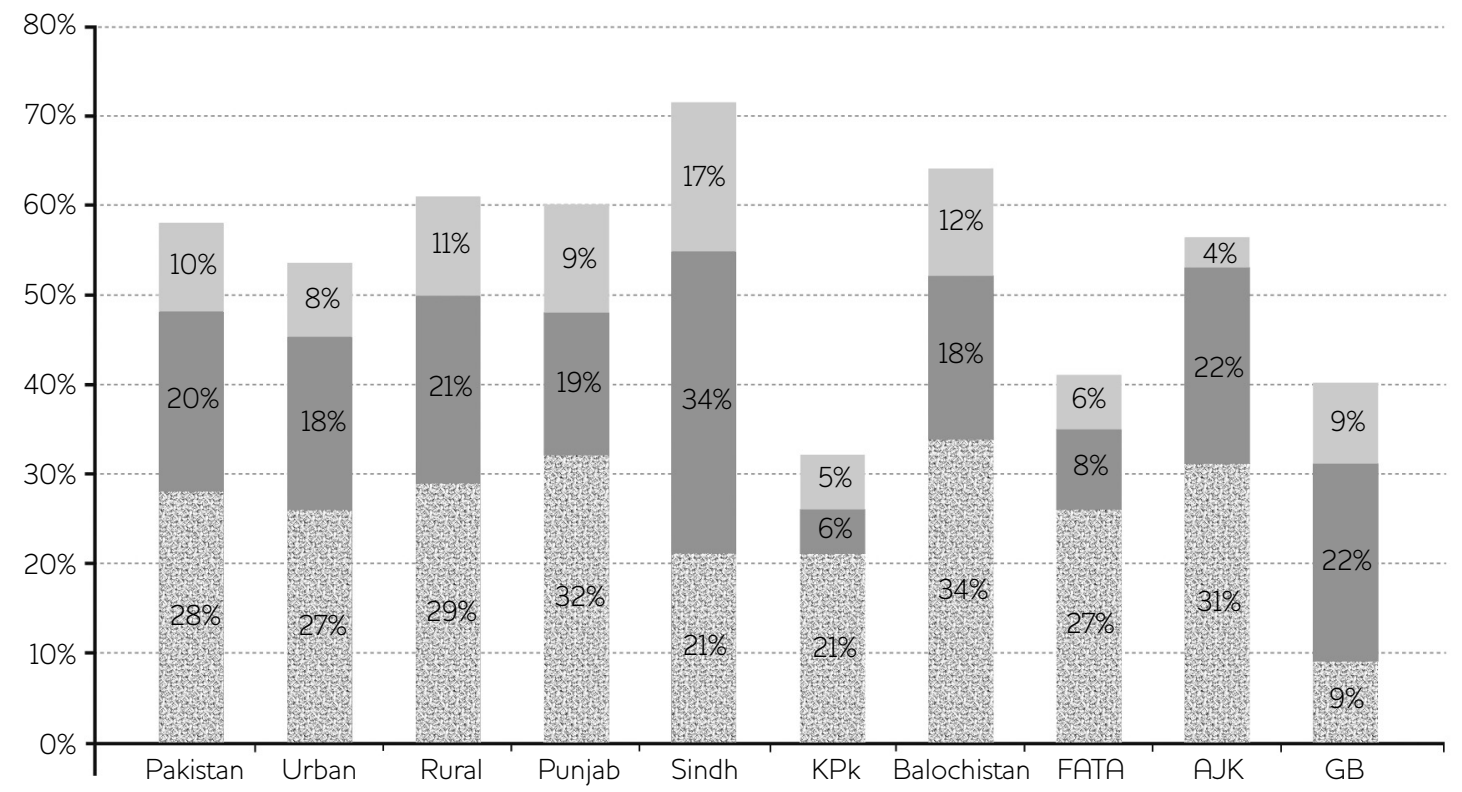

Food insecure without hunger

Food insecure with hunger (moderate)

Food insecure with hunger (severe)

Source NNS (2011).

University (AKU) in partnership with the government to assess the impacts of unprecedented flooding in that year. The results of these surveys and the methodological innovations therein - are recorded in Hossain et al. (this IDS Bulletin). The authors conclude that the surveys helped all stakeholders in 'seeing the unseen': endemic, acute and chronic malnutrition. This again shows the invisibility of undernutrition and the role that improved surveillance can play (Haddad 2012).

The relationship between income poverty and stunting rates in Pakistan is not strong (Arif et al. 2012), emphasising the need for nutritionspecific interventions, but also a need to make poverty reduction interventions more nutritionsensitive. In terms of poverty-related indicators that are more proximate to nutrition, a comparison of NNS 2011 data with NNS findings in 2001 suggests a mixed picture. The NNS 2011 data show that 64 per cent of families were residing in houses that were constructed using bricks and concrete, an increase from the NNS 2001 findings of 50 per cent. Piped drinking water was accessible to half of the households in
Pakistan in NNS 2011 (49.6 per cent), showing an improvement compared to NNS 2001 (where 41 per cent of the households reported access to tap water). However, rates of unemployment among heads of households had increased over the last decade (from 7.7 per cent in 2001 to 15.5 per cent in 2011).

An important component of the NNS 2011 was an assessment of food security using standardised questionnaires. The findings (illustrated in Figure 3) indicate wide disparities between provinces and the hitherto unappreciated burden of severe food insecurity, with hunger in 20-30 per cent of the households in some provinces. Qualitative research on poor households (Gazdar and Mallah, this IDS Bulletin) shows that these households understand food security exclusively in terms of assured access to staple grains. A comparison of a minimum food basket (Government of Pakistan 2012) with the food availability and consumption in Pakistan during 2010-11 shows that the minimum food basket and food consumption levels are well below food availability levels (Table 1). Compared to 2007, 


\begin{tabular}{llll}
\hline Food items (kg/month) & Food basket & Food availability & Consumption \\
\hline Wheat & 10.00 & 9.81 & 8.00 \\
Rice & 2.30 & 1.00 & 1.00 \\
Pulses & 1.00 & 0.60 & 0.25 \\
Sugar & 1.50 & 2.50 & 1.40 \\
Milk (litres) & 4.50 & 10.07 & 6.75 \\
Fats and oil & 1.25 & 1.00 & 1.00 \\
Meat & 1.25 & 1.40 & 0.50 \\
Fruits and vegetables & 10.50 & 6.00 & 5.25 \\
Calories (per capita/day) & 2150 & 2370 & 1700 \\
Protein (gms per capita/day) & 60 & 69 & 45 \\
\hline
\end{tabular}

Source Government of Pakistan (2012).

there has been a steady increase in the cost of the food basket, from Rs 1,000 to Rs 1,790 by

December 2011. Over the period of 2007-08 to 2008-09, there was an increase of 27 per cent in the price of the monthly food basket. For a country with high poverty (21 per cent below US $\$ 1.25$ a day purchasing power parity (PPP), down from 22.6 per cent in 2005) $)^{2}$ and unemployment, the increase in the cost of vital food items in recent years can be a factor affecting some of the poorer sectors of the population. For other poor households, particularly those in rural areas whose livelihood strategies revolve around the acquisition and storage of grain at harvest time, prices matter less (Gazdar and Mallah, this IDS Bulletin).

Using a mix of quantitative and qualitative methods, the article by Fazal et al. (this IDS Bulletin) shows that in Sindh - one of the provinces with the highest undernutrition rates these food deficits are associated with poor nutrition outcomes. Other significant correlates include access to potable water, breastfeeding, and knowledge about good nutrition practices. The nutrition causal analysis process that they use appears to be a useful analytic tool, but perhaps even more importantly a way of raising awareness about the nature and causes of undernutrition.

The article by Gazdar and Mallah (this IDS Bulletin) highlights the extreme food price inflation of the 2008-9 period and confirms the significant threat these price shocks pose when they interact with other sources of vulnerability such as illness and conflict, as well as the high cost of so-called coping strategies adopted by the most vulnerable households, which include: cutting out non-staple items, reducing food intake of some household members, migration, borrowing, begging, and women entering the workforce. When food safety nets reach the poor, they ameliorate the need for these coping strategies, but issues of coverage and timeliness undermine their effectiveness. In addition, they highlight the persistence of seasonality in food availability, employment and food insecurity.

\section{Assessment of interventions}

The dearth of impact evaluations for nutrition interventions in Pakistan is highlighted by the lack of response to the call for such articles for this Bulletin. Luckily we have two evaluations of the Tawana school feeding programme in Sindh province, which ran from 2002-05. The first is an evaluation of nutrition outcomes and the second is an evaluation of cognitive achievement outcomes. The first has no control group while the second does. The Tawana Pakistan Project (TPP) was launched in 2002 in 4,035 girls' primary schools in the rural areas of the poorest districts of Pakistan, identified from the list provided by the government to improve the nutritional status and school attendance of primary school girls. The intervention included the provision of freshly prepared balanced noon meals from locally available foods to over 418,000 girls at about US $\$ 0.12 /$ child/day. 
The first article (Hussain et al., this IDS Bulletin) is about one of the few studies undertaken to determine the prevalence of nutritional status of 5-12 year-old girls from impoverished, rural communities of Sindh province and the potential impact of a defined intervention therein. The findings suggest an improvement in the nutritional status of girls $6-12$ years of age in the poorest districts. The prevalence of wasting decreased by 14.2 per cent (from 19.7 to 5.5 per cent) and the prevalence of underweight girls also decreased by 12 per cent, from 33.9 to 21.9 per cent. Stunting did not decline. While the absence of a control group means we cannot make a causal link between Tawana and nutrition outcomes, the decline in wasting and underweight in the poorest region of Pakistan occurs during a time when those two indicators were increasing and static, respectively, during the same period in Pakistan as a whole.

The second study (Soofi et al., this IDS Bulletin) describes the effects of balanced noon meals on the cognitive abilities of the girls enrolled in the Tawana programme. The difference-in-difference results show an overall improvement - albeit small in some cases - in the literacy, numeracy and other dimensions of educational performance, of girls who were already enrolled in school. We can be more confident about the causal links between programme and outcome here, due to the control group of girls in schools who did not receive school meals. The specific mechanisms through which these improvements are generated are not clear, but they are thought to be related to greater levels of concentration due to an absence of hunger and to potentially reduced absenteeism.

It is worth noting that a school feeding programme, often thought to be a rather indirect nutrition intervention, may have had a positive impact on wasting and underweight and has definitely had an impact on cognitive achievement. While targeting the 1,000 day period remains a priority for nutrition interventions, these studies remind us that there are additional opportunities within the life cycle to intervene in an effective manner. If the Tawana programme appears to be effective, why was it stopped? We will come back to this topic in the article by Khan et al. in this IDS Bulletin.

Such causality issues are less relevant to attempts to document the accumulated effect of multiple efforts to improve a single outcome using a single instrument. This is the story of iodised salt in Pakistan (Masuood and Tausif, this IDS Bulletin). The NNS of 2001 estimated that 17 per cent of households were consuming adequately iodised salt, much lower than the rest of South Asia (over 60 per cent). The consequences of a lack of iodine include brain damage and a range of disabilities. The NNS of 2011 estimates that 69 per cent of households consume adequately iodised salt, with subsequent halving of iodine-deficiency rates of women and school-age children. What were the factors behind this remarkable revitalisation of iodisation efforts? The factors seem to be (a) government commitment; (b) adequate technical and financial support from development partners; (c) a sustained effort; and (d) indicators to assess progress and further build momentum. More analysis is needed to understand what led to the confluence of factors that brought these government and development partners together.

Nutrition status cannot be improved sustainably by nutrition-specific interventions alone.

Potentially nutrition-sensitive interventions such as agriculture and social protection programmes may be able to play a key role. The article by Balagamwala and Gazdar (this IDS Bulletin) describes the potential pathways - and disconnects - between nutrition and agriculture in Pakistan. In Pakistan, agriculture contributes to over a fifth of the gross domestic product (GDP) and it continues to employ 45 per cent of the total workforce. Can an activity that occupies so much of the workforce be made more pronutrition? Balagamwala and Gazdar identify four potentially strong disconnects:

a the high concentration of land in the hands of wealthy landowners, using less labourintensive methods and producing less food for on-farm consumption where markets work less well;

b patriarchy and unequal gender relations, disempowering women, devaluing their enterprise in agriculture and their agency in providing and purchasing nutrition inputs to their children;

c behavioural and cultural choices around diet diversity and the knowledge about, and priority given to, caring practices around infant feeding; and 
d political priorities around complementary inputs for nutrition (such as sanitation) and organisational effectiveness to develop and enforce legislation to promote wider access to land and greater gender equality.

This article also highlights important shifts in two related policy areas: food security and social protection. Government has historically been an influential player in setting the price of the main staple (wheat). Instead of using the procurement price for subsidising urban consumers, there is focus on achieving parity with world prices to ensure that local markets do not face shortages. This approach to food security has been accompanied with the introduction of a largescale cash transfer programme for women in poor households for protecting vulnerable consumers.

\section{The political economy of nutrition in Pakistan}

The politics of undernutrition reduction have long been neglected. The multitude of actors involved at many levels, together with the clinical, institutional and political invisibility of undernutrition, generates a lack of accountability for a commitment to nutrition and for the delivery of nutrition-relevant services. Pakistan is no exception to the political nature of nutrition.

Levinson (this IDS Bulletin) describes how a political opportunity - created by the floods of 2010 and 2011, the decentralisation of health services and the 2011 National Nutrition Survey - was seized by elements within the government and development partners for nutrition improvement. Factors cited for this build-up of momentum include: the ability of central government leaders and others to have fresh conversations on nutrition with more 'malleable' local government officials; better coordination and strong leadership among donors; central government commitment in the wake of the floods; the effective use of the NNS data at the provincial and sub-province levels; and the integration of advocacy in terms of the causes and consequences of undernutrition. The challenge is now to convert the momentum into action. The fragility of the opportunity is highlighted by the long list of risks identified by Levinson, including: major security concerns to divert attention, personnel changes, horizontal (across sectors) and vertical (between the centre and provinces in the post-devolution context) coordination challenges, and an inability to sustain the impetus, through a failure to mobilise civil society or embed nutrition within budgets.

A different kind of political calculation was responsible for the ending of the Tawana school feeding programme, argue Khan et al. (this IDS Bulletin). The Tawana programme was well regarded (also suggested by the two positive evaluations of it reported in this Bulletin by Hussain et al. and Soofi et al.) but was cancelled by the Government in 2006. Khan et al. argue that while the programme was not perfect, it offered a glimpse of a different way forward one that struck a balance between inclusiveness and action, transparency and accountability, and health and social science perspectives. They suggest that it was cancelled because it did not provide sufficient opportunities for leakage and diversion. In effect, they argue that the programme affected politics and was undone by political considerations. The fact that there were serious allegations of massive corruption and embezzlement ${ }^{3}$ points out to the fragility of wellmeaning programmes in a milieu of corruption and malgovernance.

Zaidi et al. (this IDS Bulletin) analyse the implications of the new post-devolution vertical coordination challenges in the context of efforts to address undernutrition. The article takes a comparative look at strategic opportunities and barriers for action on nutrition in Pakistan's four provinces - Khyber Pukhtunkhwa (KPk), Punjab, Balochistan and Sindh. Their governance analysis highlights the problems of weak coalitions for nutrition, driven by narrow conceptualisations of it, but detects signs of change not only at the central level but also in the four provinces they analyse.

They find varying capacities to address nutrition across the provinces. Punjab has supportive state actors, and strong administrative control over implementation, but movement on nutrition remains confined to health which will limit further coalition building. KPk has reorganised its Health Department around nutrition-related issues, but nutrition is yet to be a visible crosssectoral agenda, and implementation is handicapped by remote access in certain districts. Sindh and Balochistan are less well positioned. Low district accountability for nutrition is an issue in both provinces. Balochistan faces the toughest contextual 
challenges for nutrition amongst all provinces in terms of high poverty rates and low population densities for service delivery. Ironically it may have the strongest appreciation for the need for cross-sectoral action on nutrition. This article is a reminder that sound national policies are not enough to reduce undernutrition: sub-national potential and constraints need to be taken into account when strategising for nutrition.

The floods of 2010 and 2011 are mentioned in many of the articles in this Bulletin. They have been characterised as a wake-up call, a window into the unseen, and an opportunity for dialogue. Have the floods changed everything? Will they leave a lasting legacy? While emphasising that more research is needed, Siddiqi (this IDS Bulletin) argues that the floods have supported a changing social contract between the state and citizens, at least in southern Sindh where the research was conducted. She warns against adopting easy dominant narratives of the 'absent' or 'useless' state, showing how much more nuanced the reality is. She concludes that the floods 'drowned out' traditional views on the primacy of kinship or patronage-based social contract, with people immediately demanding an interaction with a state that delivers aid and institutes policy solutions. In the context of a patchy response by the state to the floods, in some areas and on some issues, the state clearly exceeded people's expectations.

\section{Conclusions}

After a lost decade, there is clearly a groundswell of momentum for nutrition in Pakistan, driven by a confluence of policy (devolution of health services), evidence (the NNS of 2011) and events (floods). This momentum needs to be sustained at the national level, reinforced at the provincial and sub-provincial levels, and then converted into actions that reduce undernutrition rapidly.

The articles in this IDS Bulletin highlight some of the key features of undernutrition in Pakistan and its drivers. The correlates of undernutrition in Pakistan are no different than any other country: poor control of infection, poor diet quality and quantity, household food insecurity, unequal gender relations, disconnects with agriculture. High levels of poverty and fragility make the context for undernutrition reduction much more difficult. Yet, the articles here also show that government-led and supported nutrition interventions can work: school feeding programmes and the iodisation of salt are the two examples highlighted here. The potential for agriculture to provide additional support is clear as long as the disconnects with nutrition can be overcome, and there are significant shifts in approaches to food security and to social protection programming which might be leveraged for pro-nutrition policy changes.

What is urgently needed now is a deepening of the understanding of nutrition and a vision for transformation at all levels of policymaking. This can lead to nutrition policies and strategies which balance nutrition-specific with nutritionsensitive interventions, underpinned by an enabling environment. Priorities have to be set that reflect a balance of technical, capacity, and political considerations.

If the logjam of malnutrition in Pakistan is to be broken, malnutrition will have to be viewed as a development outcome, one that is a foundation for other outcomes such as economic growth and social cohesion, and one that requires action on multiple fronts, not only within health. The government is not in discussion with the Scaling Up Nutrition movement about joining, and it has no specific national nutrition plan. A good signal from the government would be to have official sign-off on the National Nutrition Survey of 2011.

It is clear from the articles in this Bulletin that dealing with undernutrition is a political issue. Whenever multiple actors are involved, multiple levels of government have to be navigated, information asymmetries persist and resources are at stake, politics will follow.

One challenge is to find ways of framing nutrition that helps government officials achieve other priorities. For example, the possibility of a demographic dividend is an attractive option to many in government, as new cohorts of young people enter working age in the context of declining dependency ratios. But without adequate investment in nutrition in the first 1,000 days, the demographic dividend could turn into a demographic nightmare with a workforce ill-equipped, cognitively, to compete in an increasingly competitive region.

The nutrition community in Pakistan must not ignore the politics of nutrition - they must 
understand power, try to work with the grain and, where necessary, challenge the status quo. Only by embedding nutrition within larger policy processes such as those around economic growth,

\section{Notes}

1 Standardised Monitoring and Assessment of Relief and Transition.

2 http://data.worldbank.org/indicator/ SI.POV.DDAY (accessed 12 March 2013).

\section{References}

Arif, G.M.S.; Nazir, M.; Satti, N. and Farooq, S. (2012) Child Malnutrition in Pakistan: Trends and Determinants, Islamabad: Pakistan Institute of Development Economics

Bhutta, Z.A. (ed.) (2004) Maternal and Child Health in Pakistan: Challenges and Opportunities, Karachi: Oxford University Press

Bhutta, Z.A. and Bhutta, S.Z. (2010) 'The Unfolding Human Tragedy in Pakistan: Fighting Alone', The Lancet 376: 664-5

Bhutta, Z.A.; Hafeez, A.; Rizvi, A. et al. (2013, forthcoming) 'The Enigma of Reproductive, Maternal, Newborn and Child Health in Pakistan - Challenges and Opportunities, The Lancet

Government of Pakistan (2012) Bi-annual Report: Change in Cost of the Food Basket. July-December poverty reduction and emerging trends in social programming, will efforts to eradicate undernutrition make the transition into a sustained priority.

3 Business Recorder, 'Embezzlement in Tawana Pakistan Project: NAB Yet to Begin Investigation', 1 March, www.brecorder.com/ general-news/172/1160481/ (accessed 12 March 2013).

2011, Nutrition Section, Planning and Development Division

Haddad, Lawrence (2012) 'How Can We Build an Enabling Political Environment to Fight Undernutrition?', European Journal of Development Research 25: 13-20

NNS (2011) National Nutrition Survey of Pakistan, Islamabad: Government of Pakistan, Aga Khan University and UNICEF

NNS (2001) National Nutrition Survey of

Pakistan, Islamabad: Government of Pakistan, Pakistan Institute of Development Economics and UNICEF

Winkvist, A.; Jalil, F.; Habicht, J.P. and Rasmussen, K.M. (1994) 'Maternal Energy Depletion is Buffered among Malnourished Women in Punjab, Pakistan', J. Nutr. 124: 2376-85 